\title{
Aerosol effects on the cloud-field properties of tropical convective clouds
}

\author{
S.-S. Lee ${ }^{1,2}$ and G. Feingold ${ }^{1}$ \\ ${ }^{1}$ NOAA Earth System Research Laboratory, Chemical Sciences Division, Boulder Colorado, USA \\ ${ }^{2}$ Cooperative Institute for Research in Environmental Sciences (CIRES), University of Colorado, Boulder Colorado, USA
}

Correspondence to: S.-S. Lee (seoung.soo.lee@noaa.gov)

Received: 17 January 2013 - Published in Atmos. Chem. Phys. Discuss.: 30 January 2013

Revised: 18 May 2013 - Accepted: 2 June 2013 - Published: 17 July 2013

\begin{abstract}
Aerosol effects on condensed water and precipitation in a tropical cloud system driven by deep convective clouds are investigated for two-dimensional simulations of 2-day duration. Although an assumed 10-fold increase in aerosol concentration results in a similar temporal evolution of mean precipitation and a small (9\%) difference in cumulative precipitation between the high- and low-aerosol cases, the characteristics of the convection are much more sensitive to aerosol. The convective mass flux, and temporal evolution and frequency distribution of the condensed water path WP (sum of liquid- and ice-water paths) differ significantly between unperturbed and aerosol-perturbed simulations. There are concomitant differences in the relative importance of individual microphysical processes and the frequency distribution of the precipitation rate $(P)$. With increasing aerosol (i) the convective mass flux increases, leading to increases in condensation, cloud liquid, and accretion of cloud liquid by precipitation; (ii) autoconversion of cloud water to rain water decreases; (iii) the WP spatial distribution becomes more homogeneous; and (iv) there is an increase in the frequencies of high and low WP and $P$, and a decrease in these frequencies at the mid-range of WP and $P$. Thus, while aerosol perturbations have a small influence on total precipitation amount, for the case considered, they do have substantial influence on the spatiotemporal distribution of convection and precipitation.
\end{abstract}

\section{Introduction}

Clouds play an important role in climate change by controlling the global radiation budget and hydrological cycle. While environmental conditions are the primary determinant of clouds and convection (Bluestein, 1993; Houze, 1993), aerosol particles have also been shown to play a role. The aerosol can influence different cloud types to varying degrees and via different mechanisms, including cloud brightening, persistence of clouds, changes in cloud dynamics, and precipitation. The effects of these aerosol-cloud-precipitation interactions on climate have not been quantified adequately and represent one of the largest unknowns in climate forcing (Solomon et al., 2007). Motivated by this uncertainty, this study aims to enhance our understanding of the effect of increasing aerosol on tropical mixed-phase convective clouds. These clouds are one of the important components of the global hydrological cycle and the climate system.

Over the past decades, significant effort has been invested in development of microphysical representations of aerosolcloud-precipitation interactions in deep convective clouds (e.g., Flossmann, 1991; Respondek et al., 1995; Yin et al., 2002; Khain et al., 2005; van den Heever and Cotton, 2007; Fridlind et al., 2012; Seifert et al., 2012), and in understanding the environmental conditions in which these clouds are likely to respond to aerosol perturbations (e.g., Khain et al., 2008a; Morrison and Grabowski, 2011; Seifert et al., 2012; Tao et al., 2012). The earlier investigations simulated single cloud cells of short duration (hours) and tended to focus on microphysical interactions. Recognizing that the global hydrological circulations and climate are strongly controlled by cloud systems, which comprise multiple clouds, and last many days (Houze, 1993), more recent efforts have explored long-term (multiple days to months), large-domain simulations of convective cloud systems. These offer the promise of a more realistic view of potential aerosol influences on these systems. Cloud system studies of long 
duration or encompassing large domains have demonstrated that total precipitation amount is predominantly determined by radiative-convective equilibrium (RCE) or the applied large-scale forcing, which leads to negligible variations of the precipitation amount with varying aerosol (Grabowski, 2006; van den Heever et al., 2011; Morrison and Grabowski, 2011; Khairoutdinov and Yang, 2013).

The question posed here is thus: does the aerosol have any impact on the spatiotemporal characteristics and frequency distribution of the precipitation? The answer requires exploration of known aerosol influences on the microphysical properties of clouds and the pathways through which precipitation forms. For example, for a small change in precipitation, aerosol-induced suppression of the conversion of cloud liquid to rain via collisions among droplets (i.e., autoconversion) must be compensated by increases in other cloudliquid and cloud-ice precipitation-production pathways, each having different characteristic timescales. These compensation mechanisms are likely to involve changes in the mass of cloud liquid and cloud ice and, because of redistribution in latent heating, the spatiotemporal distribution of air mass flux, which in turn influences the distribution of condensate. These ideas find support in recent studies (e.g., van den Heever et al., 2011; Wang et al., 2011; Fan et al., 2012), which have shown that despite small influence on total precipitation amount, the variations in precipitation and WP spatiotemporal distribution and frequency induced by aerosol acting as cloud condensation nuclei were substantial. At the global scale and over sufficiently long periods of time, precipitation and evaporation must balance at the surface; therefore aerosol influences on precipitation and associated WP distribution are more relevant to the assessment of local or regional precipitation patterns/intensity than to total precipitation amount. This can have strong societal and economic impacts, as shown in the Sahel drought (Batterbury and Warren, 2001; Lee, 2011).

Motivated by the importance of the effect of aerosol on precipitation and WP distribution, this paper documents aerosol effects on the spatiotemporal distribution of clouds and precipitation in a mesoscale system comprising multiple deep convective clouds. Henceforth, this type of mesoscale system is referred to as a mesoscale cloud ensemble (MCE; Houze, 1993).

A comprehensive approach to aerosol-cloud-precipitation interactions requires simulations that are of long enough duration (as long as RCE timescales) and on a global scale in order to allow the cloud system to evolve at the full range of scales (Grabowski, 2006; Tao et al., 2012; Khairoutdinov and Yang, 2013). Idealized simulations on more limited spatiotemporal scales are nevertheless of great value since they allow more detailed resolution of convective and microphysical processes on timescales relevant to the duration of aerosol perturbations. Using an idealized framework, this study attempts to further our understanding of changes in the spa- tiotemporal distribution of clouds and precipitation induced by aerosol.

\section{Cloud-system resolving model (CSRM)}

The Goddard Cumulus Ensemble (GCE) model (Tao et al., 2003), a two-dimensional nonhydrostatic compressible model, is used here as a cloud-system-resolving model. Shortwave and longwave radiation parameterizations have been included in all simulations. The microphysical processes are represented by a double-moment bin-bulk scheme that uses bin-model-derived lookup tables for hydrometeor collection processes (Saleeby and Cotton, 2004). A gamma size distribution with fixed breadth is assumed for hydrometeor size distributions. Cloud-droplet and ice-crystal nucleation also mimic a size-resolved approach (Lee and Feingold, 2010). Aerosol is represented by a single scalar (number mixing ratio) and the assumption of a fixed (lognormal) size distribution and a fixed composition (ammonium sulfate). With this assumption, droplet nucleation is calculated based on predicted supersaturation. The cloud droplet nucleation parameterization of Abdul-Razzak and Ghan (2000, 2002), which is based on Köhler theory, is used. Aerosol particles with critical supersaturation smaller than the modelcalculated supersaturation are activated to droplets. During the simulation, aerosol is advected, diffused and processed. Through droplet or ice nucleation, aerosol mass is included in cloud liquid or cloud ice and is transferred to other species of hydrometeors through collection. Aerosol mass moves from the atmosphere to the surface when precipitating hydrometeors fall to the surface, and aerosol mass is released from hydrometeors to the atmosphere when hydrometeors evaporate or sublimate following Feingold and Kreidenweis (2002).

The effects of aerosol, both unactivated and activated, on radiative heating (i.e., aerosol direct and semidirect effects) are not taken into account.

\section{Case description}

Two-dimensional simulations of an observed mesoscale cloud ensemble (MCE; Houze, 1993) are performed over a 2-day period. The MCE was observed during a part of the Tropical Warm Pool-International Cloud Experiment (TWPICE) (12:00 LST (local solar time) 23 January-12:00 LST 25 January 2006) campaign in Darwin, Australia $\left(12.47^{\circ} \mathrm{S}\right.$, $\left.130.85^{\circ} \mathrm{E}\right)$, as described by May et al. (2008) and Fridlind et al. (2009).

Large-scale forcing for potential temperature and specific humidity is applied to the model every time step by interpolating the 3-hourly observed soundings. The observed, temporally varying surface fluxes of heat and moisture are prescribed uniformly across the surface, and are identical for all simulations. This method of modeling cloud systems was used for the CSRM comparison study by Xu et al. (2002). 
The details of the procedure for applying large-scale forcings are described in Donner et al. (1999). The horizontal momentum is damped to observed values, following $\mathrm{Xu}$ et al. (2002).

The simulations of the observed MCE have the same fundamental configuration. The horizontal domain length is set at $256 \mathrm{~km}$ in the east-west direction to capture mesoscale structures of the storm, while the vertical domain length is set at $20 \mathrm{~km}$. The horizontal grid length is $500 \mathrm{~m}$ and the vertical grid length is $200 \mathrm{~m}$. Periodic boundary conditions are applied at the horizontal boundaries.

Initial background aerosol profiles, observed during the concurrent Aerosol and Chemical Transport in Tropical Convection (ACTIVE) program (Vaughan et al., 2008) are adopted by the control run. The initial size distribution and number concentration of background aerosol are identical to those in Fig. 4 in Fridlind et al. (2009). The average background aerosol number concentration (integrated over the distribution) and over the PBL is $\sim 400 \mathrm{~cm}^{-3}$. The background aerosol concentration is $\sim 450 \mathrm{~cm}^{-3}$ at the surface, and decreases monotonically to $\sim 350 \mathrm{~cm}^{-3}$ at the top of the PBL. To examine the aerosol effect, the control run is repeated but only the aerosol number concentration is enhanced by a factor of 10 . This simulation is referred to as the "high-aerosol run". This rather significant perturbation reflects something akin to a major biomass-burning event rather than a sustained perturbation over the course of months; it is therefore appropriate for the relatively short 2day simulations. To test the robustness of results to lower aerosol perturbations, the control run is repeated with aerosol number concentration enhanced by a factor of 3 ; this simulation is referred to as "the medium-aerosol run".

\section{Results}

\subsection{Precipitation, condensation and updrafts}

Figure 1 depicts the time series of the area-mean precipitation rate $P$, smoothed over $3 \mathrm{~h}$ for all simulations, compared to observations. As expected, the precipitation is simulated reasonably well because of the strong meteorological control on $P$. The simulated cloud fractions for low clouds $(0-5 \mathrm{~km})$, medium clouds $(5-10 \mathrm{~km})$, and high clouds $(10-15 \mathrm{~km})$ are within a few percent of observations: $45 \%$ (low), $55 \%$ (mid), and $78 \%$ (high) in the control run, compared to $43 \%$ (low), $52 \%$ (mid), and $81 \%$ (high) in the observations. The simulated average cloud-top height over the simulation period is $8.5 \mathrm{~km}$, while the observed height is $7.8 \mathrm{~km}(\sim 8 \%$ difference). The time- and domain-averaged liquid-water path (LWP) and ice-water path (IWP) are 920 and $85 \mathrm{~g} \mathrm{~m}^{-2}$, respectively, which are $\sim 11 \%$ and $9 \%$ different from the observed LWP (819) and IWP $\left(77 \mathrm{~g} \mathrm{~m}^{-2}\right)$, respectively. These comparisons provide confidence that the overall MCE structure is simulated reasonably well.
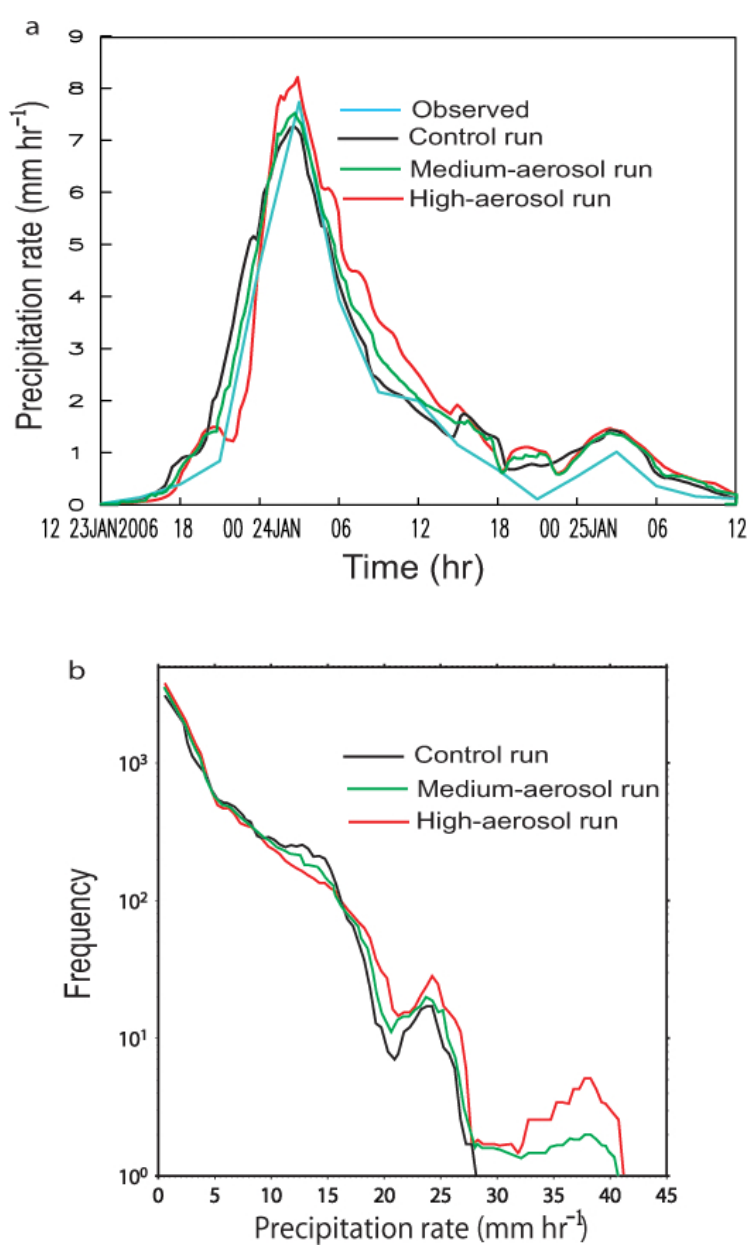

Fig. 1. (a) Time series of precipitation rate $(P)$ and (b) frequency distribution of $P$.

The average cumulative precipitation over the domain at the last time step for the high-aerosol run $(95.7 \mathrm{~mm})$ and the medium-aerosol run $(90.1 \mathrm{~mm})$ is $\sim 9 \%$ and $\sim 2 \%$ greater than that for the control run, respectively. Increasing the aerosol concentration enhances precipitation, but these differences in precipitation are quite small compared to the 10and 3-fold increases in aerosol concentration. This is similar to findings in Grabowski (2006), van den Heever et al. (2011) and Morrison and Grabowski (2011).

Following Lee et al. (2008a), we calculate differences in the domain-average cumulative sources and sinks of the sum of precipitable hydrometeors between the highaerosol run and control run (high-aerosol-control) and between the medium-aerosol run and control run (mediumaerosol-control) to elucidate the microphysical processes leading to the relatively small difference in total precipitation amount. Among the sources and sinks, autoconversion and terms associated with accretion of cloud liquid account for the primary differences in the precipitation amount (Lee et al., 2008b; Lee and Feingold, 2010). Autoconversion is 
suppressed, whereas accretion of cloud water increases in response to the aerosol perturbation. The increase in accretion is supported by substantial increases in condensation (30$40 \%$ ) and associated cloud liquid (Lee et al., 2008b). Accretion of cloud ice by precipitation also increases with increasing aerosol; however, this increase is $\sim 1$ order of magnitude smaller than the cloud-liquid accretion increase. The enhancement in accretion is slightly greater than the decrease in autoconversion and increase in evaporation and associated cloud-liquid loss. On balance the result is a small increase in the integrated precipitation amount in response to increasing aerosol. It is noteworthy that none of the primary budget terms includes the less well-known cloud-ice and ice-ice interactions; however, this may change in the future as our knowledge of these processes improves.

The precipitation efficiency (cumulative precipitation normalized with respect to cumulative condensation at the end of time integration) is $0.40,0.45$, and 0.51 in the high- and medium-aerosol and control runs, respectively. The high- and medium-aerosol runs produce slightly larger cumulative precipitation in spite of the lower efficiency of rain production (Lee and Feingold, 2010). The small increase in the precipitation amount in this system is made possible by the substantial increase in condensation, which dominates the reduced efficiency with which cloud liquid is converted to precipitation. Condensation is closely linked to the dynamic intensity of a system, which suggests commensurate response in metrics of the system dynamics. Figure $2 \mathrm{a}$ and $\mathrm{b}$ show the timeand domain-averaged vertical distribution of updraft mass fluxes and the time series of the average updraft mass fluxes. The high- and medium-aerosol runs show significantly increased updraft mass fluxes, consistent with substantially increased condensation.

Figure $1 \mathrm{~b}$ shows the frequency distribution of $P$. Although variations in cumulative precipitation between the three runs are very small for the strong aerosol perturbations, the frequency distribution of $P$ shows features that clearly differentiate the high- or medium-aerosol run from the control run (Fig. 1b). For the interpretation of this analysis, $P$ is classified as light $\left(P<5 \mathrm{~mm} \mathrm{~h}^{-1}\right)$, moderate $(P$ between 5 and $\left.15 \mathrm{~mm} \mathrm{~h}^{-1}\right)$, and heavy $\left(P>15 \mathrm{~mm} \mathrm{~h}^{-1}\right)$. The most conspicuous differences in the precipitation frequency distribution between the runs are (i) for the heavy $P$ between $\sim 15 \mathrm{~mm} \mathrm{~h}^{-1}$ and $\sim 28 \mathrm{~mm} \mathrm{~h}^{-1}$, and the high- and mediumaerosol run have $\sim 40 \%$ and $\sim 25 \%$ larger precipitation frequency than the control run, respectively. Precipitation rates $>28 \mathrm{~mm} \mathrm{~h}^{-1}$, although relatively rare in the perturbed simulations, do not exist in the control simulation; (ii) for light precipitation, the high- and medium-aerosol run show on average $\sim 30 \%$ and $20 \%$ larger frequency than the control run, respectively; and (iii) for moderate rain rates, the control run shows on average $\sim 35 \%$ and $21 \%$ larger precipitation frequency than the high- and medium-aerosol runs, respectively. The high- and medium-aerosol runs respond to the aerosol perturbation in a qualitatively similar way (Figs. 1 and 2,
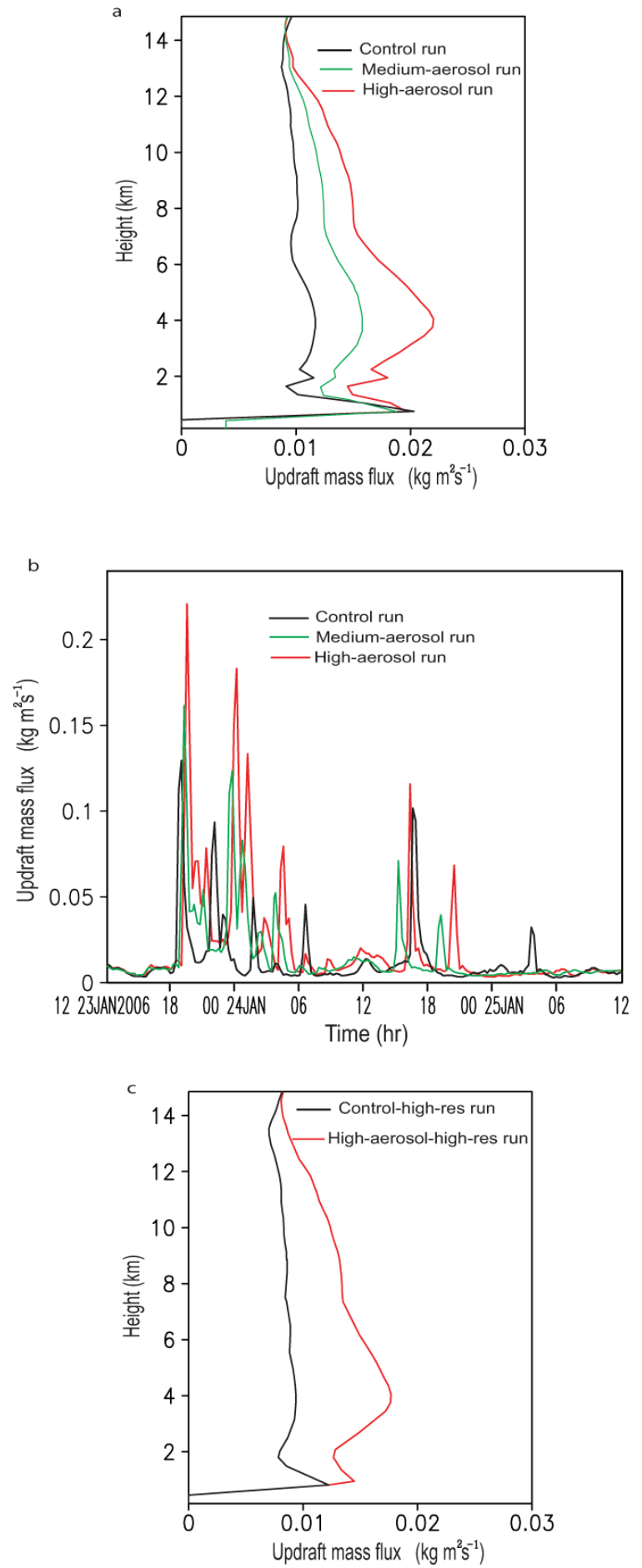

Fig. 2. (a) Vertical distribution of updraft mass fluxes and (b) time series of updraft mass fluxes, averaged over grid cells with positive vertical velocities. (c) As in (a) but for the control-high-res and high-aerosol-high-res runs. 

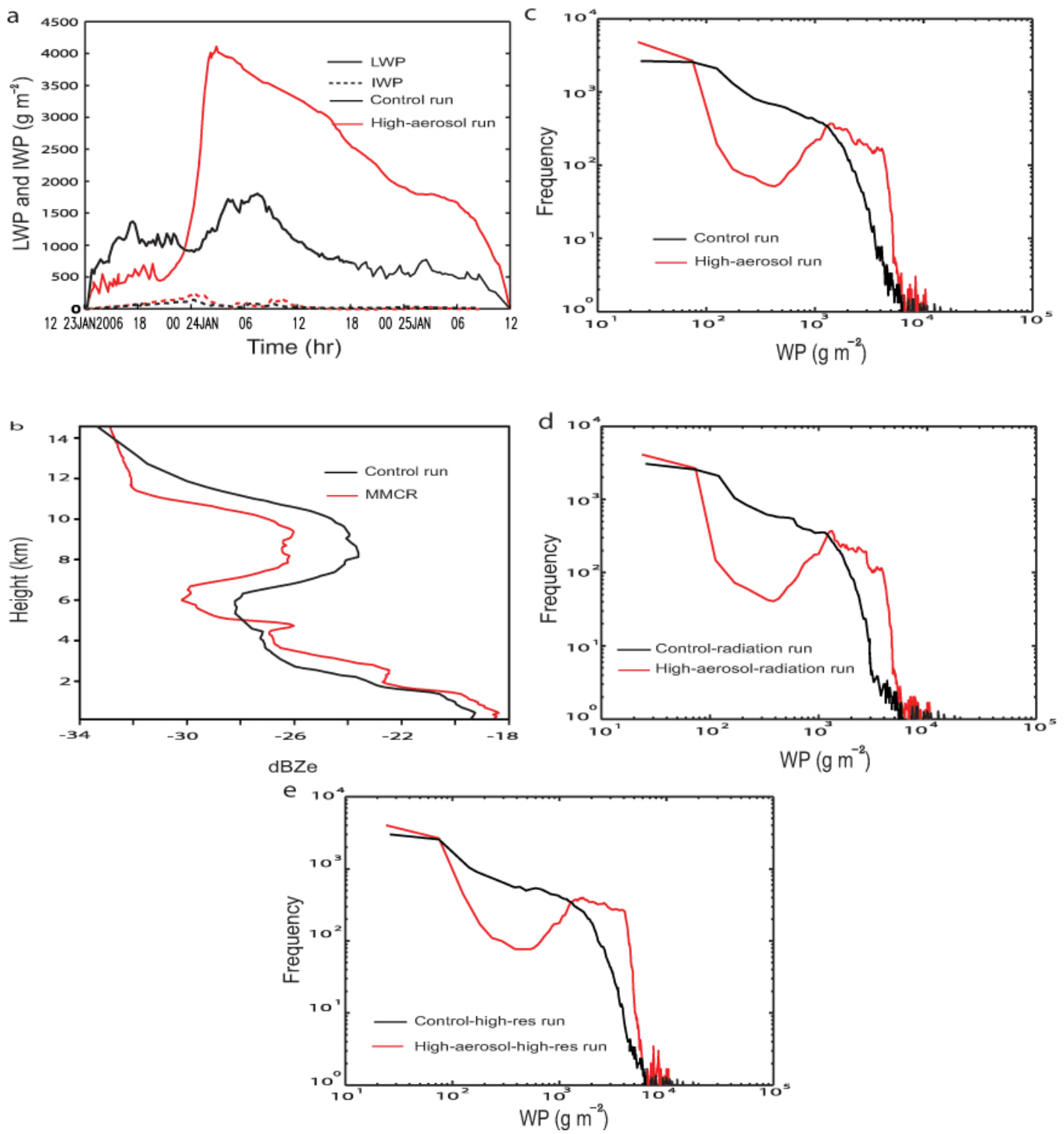

Fig. 3. (a) Time series of liquid-water path (LWP) and ice-water path (IWP), (b) vertical distribution of the time- and domain-averaged radar reflectivity (units: $\mathrm{dBZ}_{\mathrm{e}}$ ) in the control run and the time-averaged radar reflectivity from a millimeter wave cloud radar (MMCR) and (c) frequency distribution of water path (WP = LWP + IWP) for the entire simulation period for the control and high-aerosol runs. (d) As in (c) but for the fixed radiation simulations (control-radiation, high-aerosol-radiation); (e) as in (c) but for the high-resolution simulations (control-high-res and high-aerosol-high-res).

discussions in this section, as well as further analyses in subsequent sections). Hence, results from the high-aerosol and control runs will hereafter be the focus of analysis and discussion.

\subsection{Water path}

\subsubsection{Time series, frequency distribution, and power spectral analysis}

We showed in the previous section that condensation and evaporation are altered by aerosol significantly. Since condensation and evaporation are dominant source and sink of cloud mass, we explore aerosol influences on condensed cloud mass, as represented by LWP and IWP. Figure 3a shows the time series of the domain-averaged LWP and IWP 

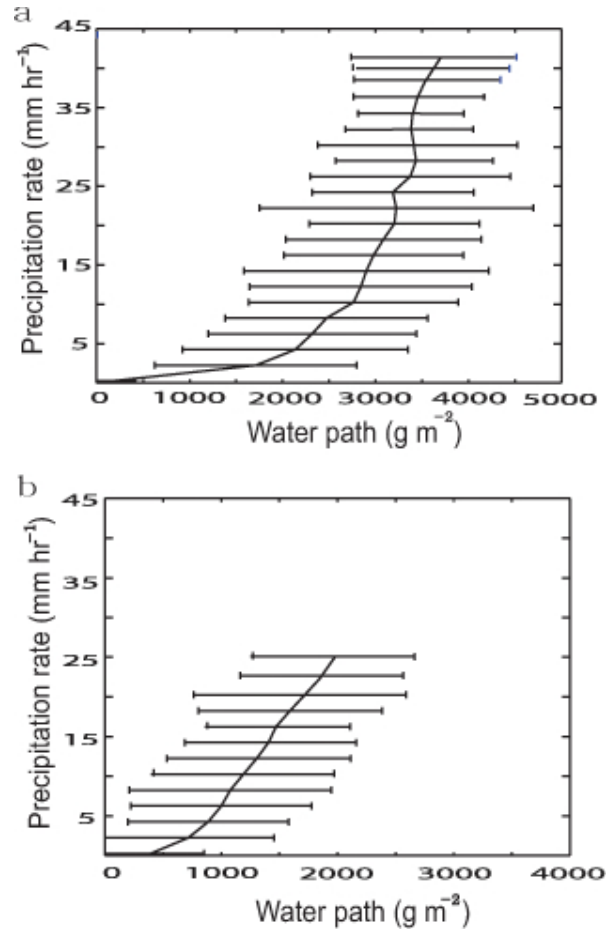

Fig. 4. Averaged WP for (a) the high-aerosol run and (b) the control run. Vertical bars represent \pm 1 standard deviation.

over the simulation period. It is clear that LWP accounts for most of the water path (WP $=$ LWP + IWP) and that the LWP differences are correlated with the precipitation differences, albeit with a lag of $\sim 40 \mathrm{~min}$ (cf. Figs. 1a and 3 a). This lag time is associated with the delay time required for precipitation to form and fall to the ground.

To evaluate the model simulation of cloud particles (e.g., cloud-liquid and cloud-ice particles), radar reflectivity from a millimeter wave cloud radar (MMCR) (Seo and Liu, 2006) is compared to the simulated radar reflectivity for the control run (Fig. 3b). Figure 3b demonstrates that simulated radar reflectivity follows the vertical distribution of the MMCR reasonably well.

Figure $3 \mathrm{c}$ shows the frequency distribution of WP. As in the case of $P$, the high-aerosol run is characterized by (i) a higher frequency of high WP $\left(>1000 \mathrm{~g} \mathrm{~m}^{-2}\right)$, (ii) a lower frequency of events in the midrange of WP between $\sim 100$ and $1000 \mathrm{~g} \mathrm{~m}^{-2}$, and (iii) a higher frequency of low WP $\left(<100 \mathrm{~g} \mathrm{~m}^{-2}\right)$ (cf. Fig. 1b). It is worth pointing out that there is also a higher frequency of high cloud-top heights $(>8 \mathrm{~km})$, a lower frequency of medium cloud-top heights between $4 \mathrm{~km}$ and $8 \mathrm{~km}$, and a higher frequency of low cloudtop heights $(<4 \mathrm{~km})$ in the high-aerosol run. This indicates a correlation between the WP and cloud-top height distributions.

Grid columns with a specific $P$ are collected over the course of the 2-day simulation. Then, the mean and the standard deviation of WP over these columns are calculated. This
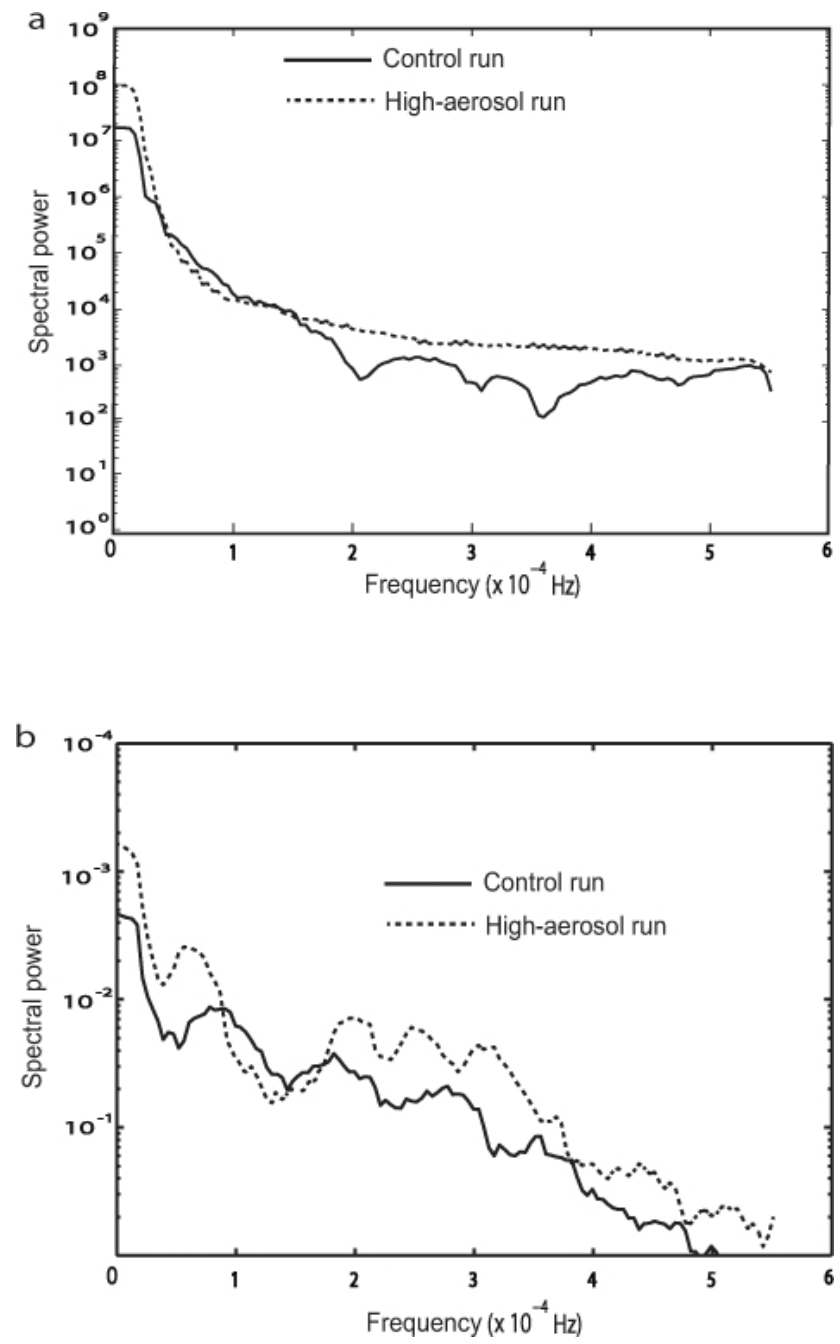

Fig. 5. Power spectral analyses of (a) the WP time series and (b) the updraft-mass-flux time series.

calculation is performed for $P$ between 0 and $45 \mathrm{~mm} \mathrm{~h}^{-1}$, discretized into linearly distributed bin values. Note that $45 \mathrm{~mm} \mathrm{~h}^{-1}$ corresponds to the maximum precipitation rate in the two simulations. Figure 4 shows the mean and standard deviation of WP for the discretized $P$ between 0 and $45 \mathrm{~mm} \mathrm{~h}^{-1}$. Figure 4 demonstrates that, as expected, larger $P$ is associated with larger WP, consistent with the correlations in differences in WP and those in $P$ in Figs. 1 and 3. It is noteworthy that the rate of the $P$ increase with increasing WP is higher in the control run. Stated differently, the clean aerosol conditions produce higher $P$ 's than the high-aerosol conditions for the same WP. This reflects the higher precipitation efficiency in clean conditions as discussed in depth in Lee and Feingold (2010).

Figure 5a shows the power spectral analysis based on the domain-averaged WP time series (Fig. 3a). First, at the lowest frequencies (spatial scales $\sim 250 \mathrm{~km}$ based on the average advection speed of $10 \mathrm{~m} \mathrm{~s}^{-1}$ ), the high-aerosol run exhibits 

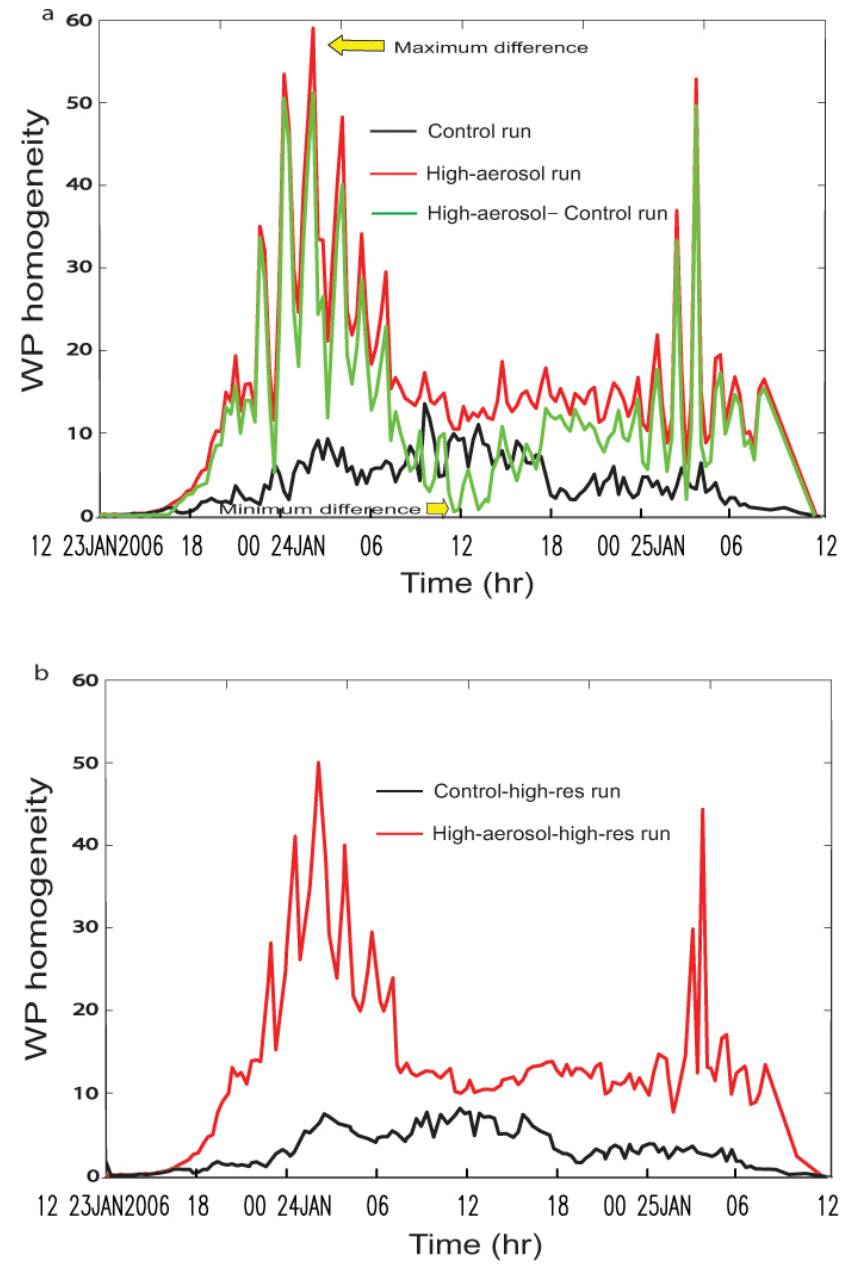

Fig. 6. Time series of the WP homogeneity (a) for the control and high-aerosol runs and (b) for the control-high-res and high-aerosolhigh-res runs.

larger spectral power; second, it is notable that in the highaerosol run, the power is larger and distributed more homogeneously for frequencies $>\sim 1.6 \times 10^{-4} \mathrm{~Hz}$ (spatial scales $<\sim 70 \mathrm{~km}$ ). However, between $\sim 0.5 \times 10^{-4}$ and $\sim 1.6 \times$ $10^{-4} \mathrm{~Hz}$, the control run exhibits greater power. Similar to these differences in the WP power, when the power spectral analysis is performed on the updraft-mass-flux time series (Fig. 2b), the high-aerosol run has larger power throughout the frequency range except for that between $\sim 0.8 \times 10^{-4}$ and $\sim 1.8 \times 10^{-4} \mathrm{~Hz}$ (Fig. 5b).

\subsubsection{Homogeneity}

Following Barker (1996), a nondimensional homogeneity parameter $H_{\sigma}$ is used to quantify the spatial homogeneity of cloud fields. $H_{\sigma}$ is defined as $\left(\frac{\bar{A}}{\sigma_{A}}\right)^{2}$, where $\bar{A}$ and $\sigma_{A}$ represent the spatial mean and standard deviation of $A$ at a certain time, respectively, and $A$ denotes the variable under consideration. $H_{\sigma}$ of WP is calculated at each time step, and the
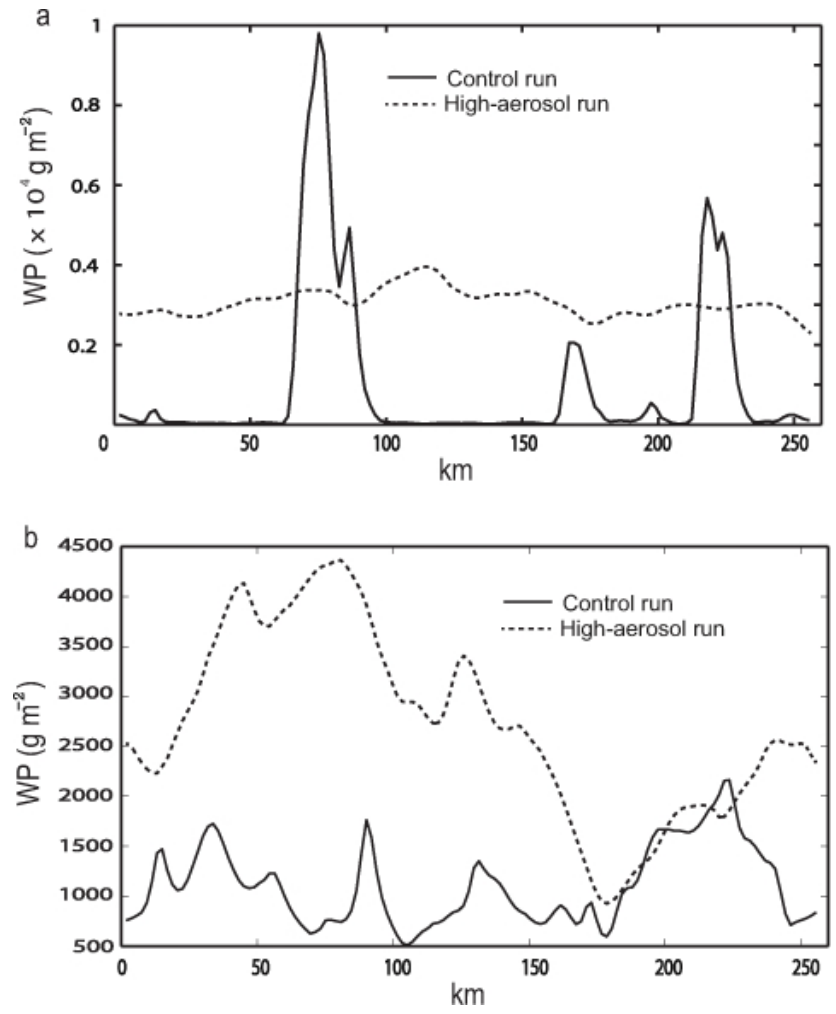

Fig. 7. Spatial distribution of WP over the horizontal domain (a) at the time of maximum difference around 03:00 LST on 24 January in the WP homogeneity and (b) at the time of minimum difference in the WP homogeneity around 12:00 LST on 24 January.

time series of $H_{\sigma}$ is shown in Fig. 6a. Throughout the simulation period, $H_{\sigma}$ of the high-aerosol run exceeds that of the control run.

It is interesting to examine the differences in the spatial distribution of WP when differences in the homogeneity between the two runs are either at their maximum or their minimum during the simulation period (Fig. 7a and b). The maximum and minimum differences in homogeneity between the two simulations occur around 02:00 LST and 12:00 LST on 24 January (marked by arrows in Fig. 6a), respectively. At the time of the maximum difference in $H_{\sigma}$, WP fluctuates with little deviation around $\sim 3500 \mathrm{~g} \mathrm{~m}^{-2}$ in the high-aerosol run. However in the control run, WP varies widely from 0 to $\sim 10000 \mathrm{~g} \mathrm{~m}^{-2}$ and is associated with three distinct peaks in WP (Fig. 7a). At the time of the minimum difference in the WP homogeneity (Fig. 7b), WP is generally larger in the high-aerosol run. However, in contrast to Fig. 7a, there are no distinct differences in the WP spatial variations between the simulations.

The much larger homogeneity of WP in the high-aerosol run at the time of the maximum $H_{\sigma}$ difference is reflected in the power spectral analysis on the spatial distribution of WP over the domain. (Note that this differs from the power spectra calculated from the domain-averaged time 

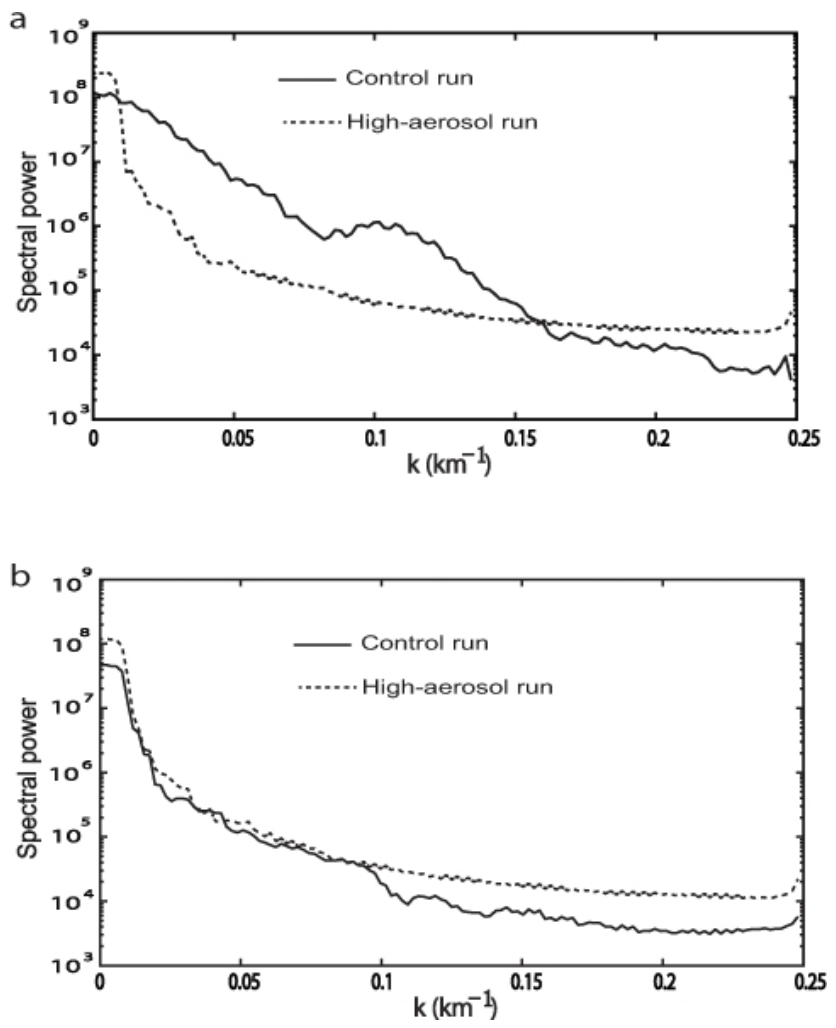

Fig. 8. Spectral power of spatial WP distribution (a) at the time of the maximum difference around 03:00 LST on 24 January in the WP homogeneity and (b) at the time of the minimum difference around 12:00 LST on 24 January in the WP homogeneity.

series in Fig. 5.) Figure 8a shows that at the time of the maximum difference in $H_{\sigma}$, the spectral power in the highaerosol run concentrates at small wavenumbers $(k)$; it exhibits much less variability compared to the control run than in the range between $\sim 0.05$ and $0.25 \mathrm{~km}^{-1}$ (or $\sim 4$ to $20 \mathrm{~km}$ when translated to a spatial scale). In this range, the control run power spectrum exhibits a distinct peak around $k=$ $0.12 \mathrm{~km}^{-1}(\sim 8 \mathrm{~km})$ and a large decrease in the power thereafter. Overall the perturbed case concentrates more energy in the smallest and largest wavenumbers. These differences are consistent with the homogeneous spatial variation of WP for the perturbed case at the time of the maximum difference (Fig. 7a).

At the time of minimum difference in homogeneity, the difference in the distribution of power over the entire $k$ range between the high-aerosol and control runs is relatively small, although there is a slight decrease in power for $k$ of $\sim 0.1 \mathrm{~km}^{-1}$ or above in the control run.

The WP frequency distribution at the time of maximum differences in homogeneity (Fig. 9a) is much wider in the control run, as expected from Fig. 7a. While convective cells with moderate WP are spread throughout the domain in the high-aerosol run, in the control run, convective cells with very large WP are interspersed with those with very
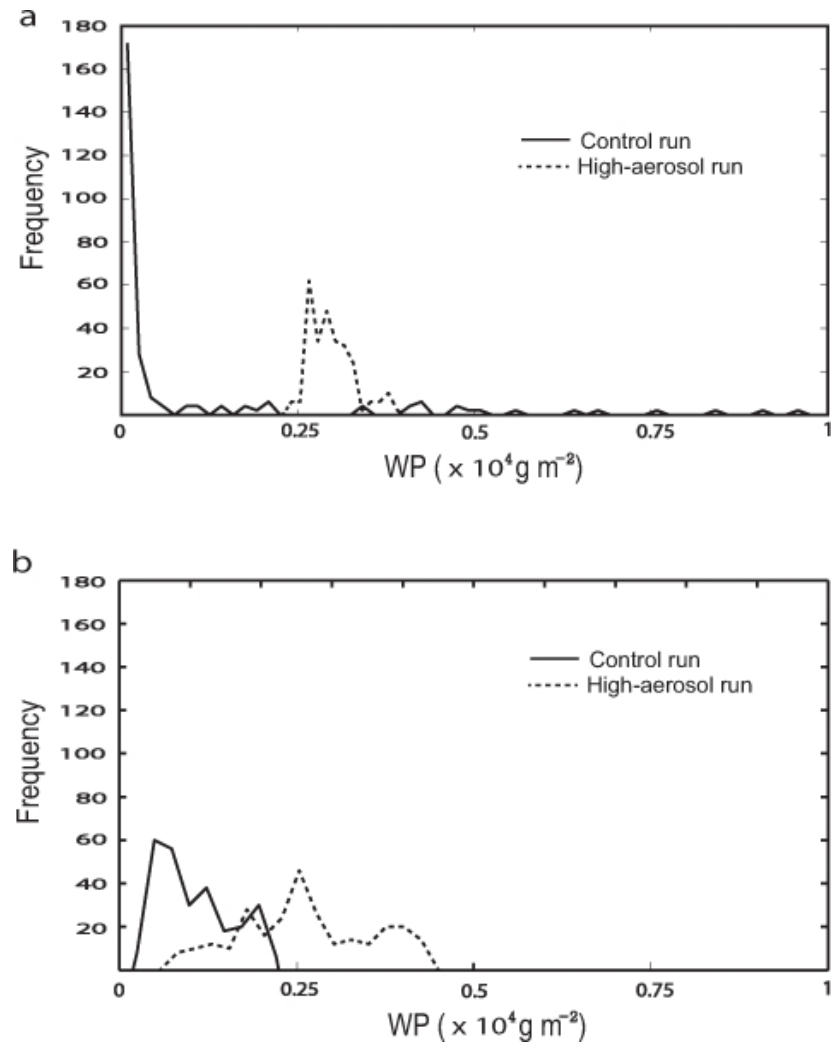

Fig. 9. Frequency distribution of WP (a) at the time of maximum difference in homogeneity around 03:00 LST on 24 January and (b) at the time of minimum difference in homogeneity around 12:00 LST on 24 January.

small WP (Figs. 7a and 9a). This reflects substantial aerosolinduced changes in cloud-field properties. At the time of the minimum homogeneity difference (Fig. 9b), the WP frequency is spread over a similar range for both of the runs, with a shift to larger WP values in the perturbed case, as expected from Fig. $7 b$.

\subsubsection{Temporal evolution of the WP frequency}

The WP frequency distribution is now calculated for three separate time segments over the course of the 2-day simulation. The first, second, and third segments are 12:00 LST on 23 January-00:00 LST on 24 January, 00:00 LST on 24 January-18:00 LST on 24 January, and 18:00 LST on 24 January-12:00 LST on 25 January, respectively. The segments correspond to initial, mature, and decaying stages of convective activity based on the precipitation evolution in Fig. 1a. Precipitation starts and increases in the initial stage and reaches its maximum value in the mature stage. In the decaying stage, precipitation stabilizes to a low level and does not vary much.

For the first segment, there are significant differences in the WP frequency for WP between 0 and $\sim 100 \mathrm{~g} \mathrm{~m}^{-2}$ (Fig. 10a); however there are negligible differences for WP 

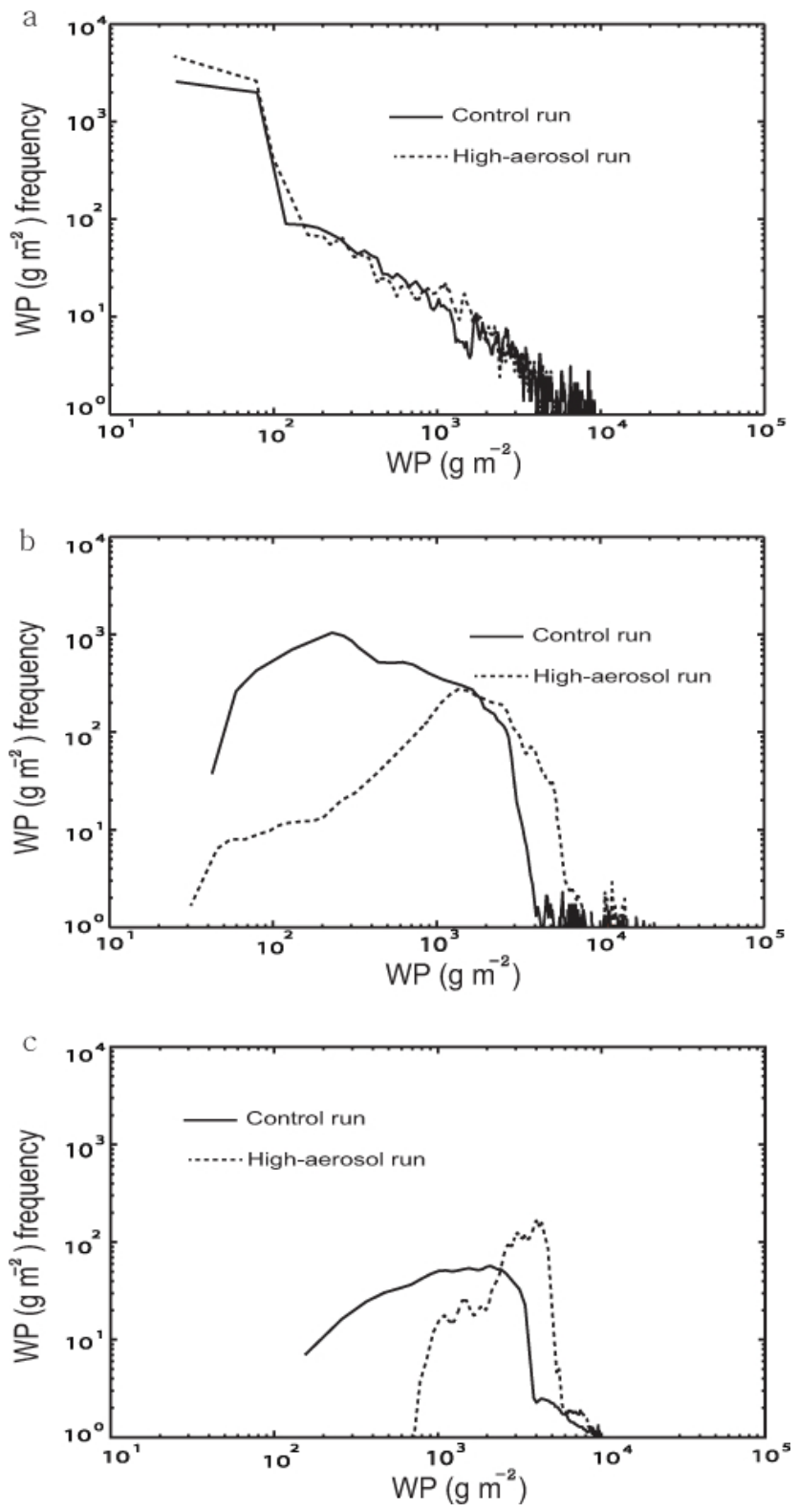

Fig. 10. Frequency distribution of WP over a period (a) between 12:00 LST on 23 January and 00:00 LST on 24 January, (b) between 00:00 LST on 24 January and 18:00 LST on 24 January, and (c) between 18:00 LST on 24 January and 12:00 LST on 25 January.

$>\sim 100 \mathrm{~g} \mathrm{~m}^{-2}$. In the second segment, significant differences in the WP frequency distribution are evident (Fig. 10b), with a tendency for the perturbed simulation to be characterized by more frequent higher, and fewer small WP events. In the third segment, the distributions qualitatively resemble those in the second segment (Fig. 10c), although both are narrower, particularly that of the perturbed simulation. Note that there are no occurrences of WP $<100 \mathrm{~g} \mathrm{~m}^{-2}$ for both of the runs. Figure 10 shows that the difference in the occurrence of low WP $<\sim 100 \mathrm{~g} \mathrm{~m}^{-2}$ appears during the ini-
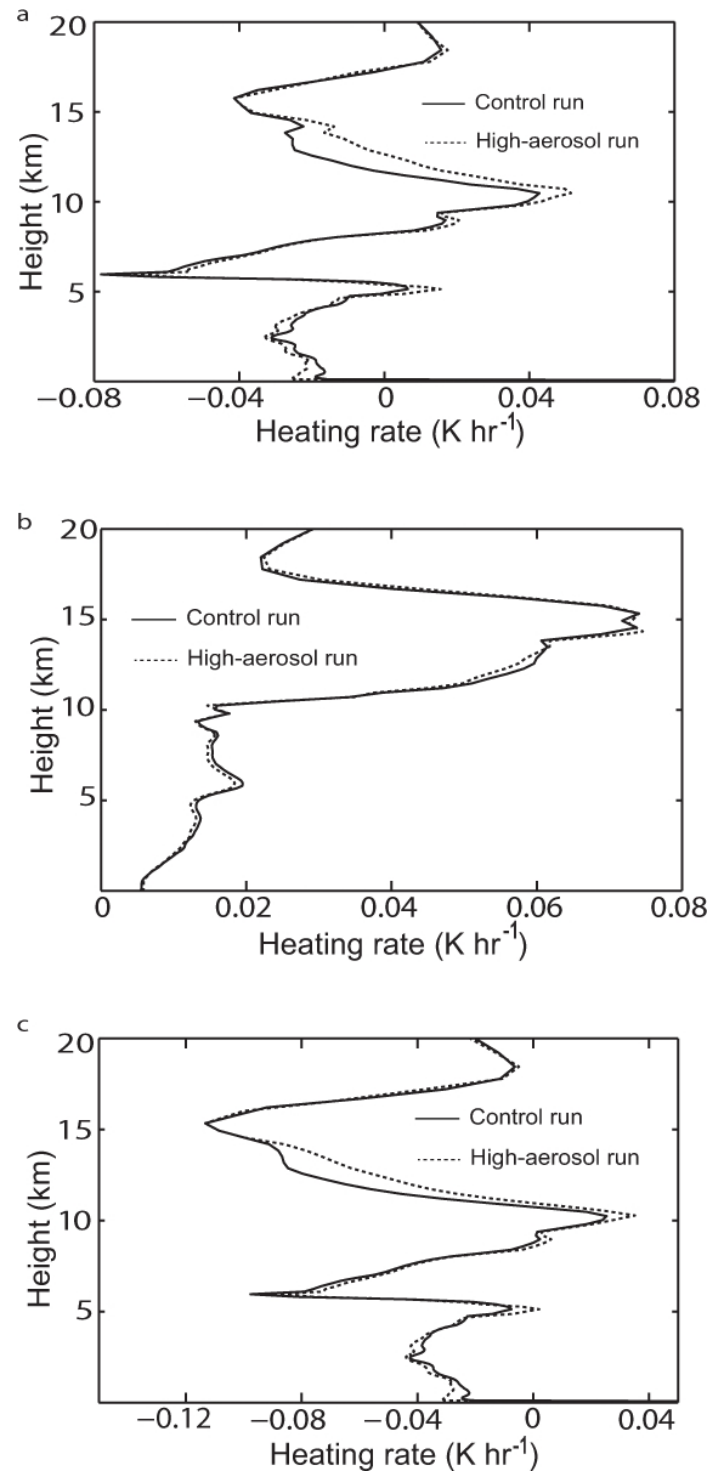

Fig. 11. Vertical distributions of the time- and domain-averaged (a) net radiative, (b) shortwave radiative, and (c) longwave radiative heating rates.

tial stage, while the difference in the occurrence of moderate WP clouds with $100 \mathrm{~g} \mathrm{~m}^{-2}<\mathrm{WP}<1000 \mathrm{~g} \mathrm{~m}^{-2}$ occurs during the mature stage. For clouds with high WP $>1000 \mathrm{~g} \mathrm{~m}^{-2}$, the difference is mostly manifested during the mature and decaying stage of convective activity.

\subsubsection{Radiation}

The time- and domain-averaged shortwave and longwave fluxes at the top of domain are -109.2 and $129.5 \mathrm{~W} \mathrm{~m}^{-2}$, respectively, in the high-aerosol run. Here, minus and plus represent downward and upward fluxes, respectively. The equivalent shortwave and longwave fluxes in the control run are -118.5 and $133.2 \mathrm{~W} \mathrm{~m}^{-2}$. With increasing aerosol, net 
radiation fluxes at the domain top (i.e., shortwave plus longwave fluxes) increase from 14.7 to $20.3 \mathrm{~W} \mathrm{~m}^{-2}$, mainly due to more reflection of incident shortwave radiation at the top in the high-aerosol run. However, it should be pointed out that $\sim 40 \%$ of the increase in the reflection of shortwave radiation is offset by a decrease in the outgoing longwave radiation at the top with increasing aerosol. This offset is an order of magnitude larger than that in warm stratocumulus clouds (e.g., Lee et al., 2009).

Figure 11a shows vertical distributions of the time- and domain-averaged radiative heating rates. Net heating rates (i.e., shortwave plus longwave heating rates) show generally larger and smaller heating above and below $\sim 5 \mathrm{~km}$, respectively, in the high-aerosol run (Fig. 11a). The larger heating above $5 \mathrm{~km}$ dominates the smaller heating below $5 \mathrm{~km}$ in the high-aerosol run, leading to the larger time- and domain-averaged net heating $\left(-1.23 \mathrm{~K} \mathrm{~h}^{-1}\right)$ than in the control run $\left(-1.41 \mathrm{~K} \mathrm{~h}^{-1}\right)$. Comparisons amongst Fig. 11a, b, and $\mathrm{c}$ demonstrate that differences in the net heating between the runs are mostly caused by those in longwave heating. They also show that in the high-aerosol run the time- and domain-averaged shortwave heating is lower, and thus the larger net heating is enabled by higher longwave heating.

Figure 12a shows the vertical distribution of the time- and domain-averaged sum of liquid-water and ice-water content. Only the water content of cloud liquid and cloud ice are included in Fig. 12a; that is, the water content of precipitable hydrometeors such as rain, snow, graupel, and hail is not included. However, inclusion of precipitable hydrometeors shows similar qualitative results (e.g., homogeneity). Above $\sim 9 \mathrm{~km}$, the level of homogeneous freezing, most of the sum is accounted for by ice water, while below $\sim 9 \mathrm{~km}$ most is accounted for by liquid water. Figure $12 \mathrm{~b}$ shows the vertical distribution of the time- and domain-averaged net longwave flux. The larger net longwave flux in the high-aerosol run becomes smaller than that in the control run around $10 \mathrm{~km}$ due to larger ice mass blocking more upward longwave flux. This induces the smaller outgoing longwave radiation at the model top and plays a critical role in the larger longwave heating.

Figure $3 \mathrm{~d}$ shows the frequency distribution of WP from the repeated control and high-aerosol runs with explicit radiation calculations turned off, but with the average heating rate from the high-aerosol run (shown in Fig. 11a) imposed on all grid points in both of the repeated runs. Hence, there are no differences in radiative heating between these repeated runs (the "control-radiation" run and the "highaerosol-radiation" run). There are no qualitative differences between Fig. 3c and d, which exemplifies that aerosolinduced changes in radiative heating rates do not influence the qualitative nature of results discussed in the previous sections.
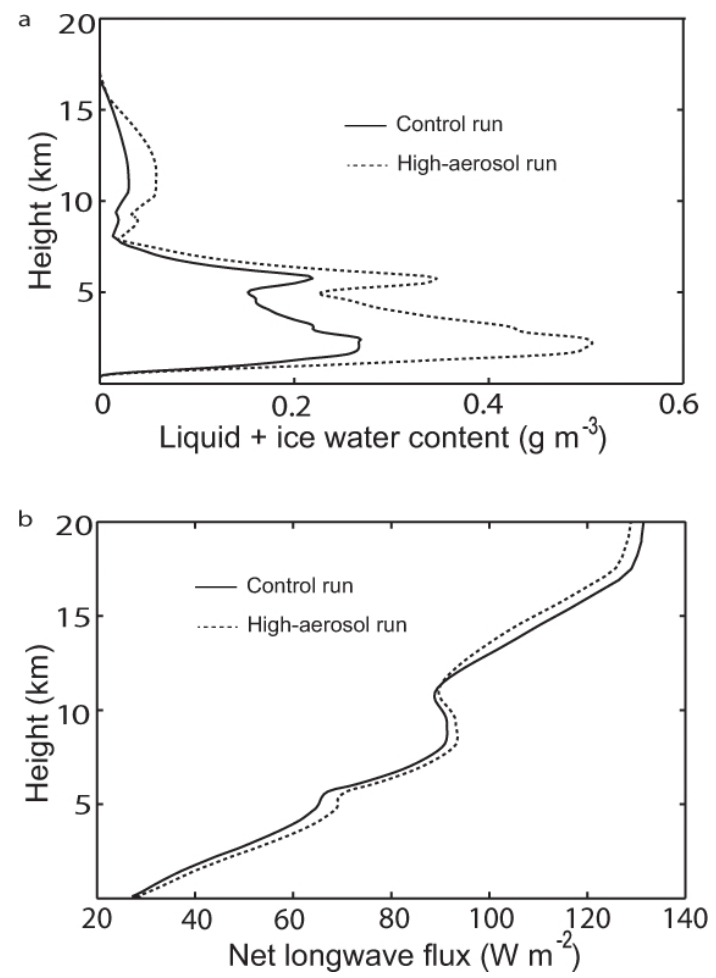

Fig. 12. Vertical distributions of the time- and domain-averaged (a) sum of liquid- and ice-water content and (b) net longwave flux. Water content of precipitable hydrometeors such as rain, snow, graupel, and hail is not included in (a).

\section{Discussion}

\subsection{Updraft mass flux}

This study shows that mass fluxes associated with the highaerosol run are approximately 2 times larger than those from the low-aerosol run (Fig. 2). In contrast, Morrison and Grabowski (2011) show negligible differences in updraft mass fluxes between their high- and low-aerosol experiments for the same TWP-ICE case. Their high-aerosol case has $\sim 20$ times larger aerosol concentration than their low-aerosol case. This implies that in their simulations the increase in condensation (in response to that in updrafts) and the subsequent increase in accretion of cloud liquid may not be a primary compensation mechanism. (Note that Morrison and Grabowski, 2011, also showed a nearly identical precipitation amount between the high- and low-aerosol cases.) However, in agreement with this study, van den Heever et al. (2011) simulated $\sim 2$ times larger updrafts with 16 times higher aerosol concentration for tropical clouds in radiative convective equilibrium (RCE). Morrison and Grabowski (2011) and this study adopt different simulation setups (e.g., resolution and domain size) and different microphysics parameterizations. van den Heever et al. (2011) and this study use approximately the same microphysical 
scheme. To gain a more comprehensive understanding of the mass flux response and the compensation mechanism, future work will examine the sensitivity of the mass-flux response to the simulation setup and microphysics parameterization.

\subsection{Precipitation frequency}

Previous studies (e.g., Fan et al., 2012; van den Heever et al., 2011; Wang et al., 2011; Koren et al., 2012; and Li et al., 2011) examining the response of the $P$ frequency to aerosol in deep convective clouds reaching the tropopause used different criteria to classify $P$. Note that while Fan et al. (2012), van den Heever et al. (2011), and Wang et al. (2011) rely on models for the $P$ frequency calculation, Koren et al. (2012) and Li et al. (2011) used satellite and ground-based observations for their calculations. The maximum $P$ in those studies are different to this study, as are the classifications into $P$ ranges. The significantly different classifications exacerbate comparisons among studies. Nevertheless, there is good agreement amongst the abovementioned studies and this study that an increase in aerosol enhances the frequency of relatively heavy precipitation. However, in other ranges of $P$, there are discrepancies in the response of the $P$ frequency. This may not be that surprising considering significant differences in the development stages of convection and environmental conditions among studies as well as the strong dependence of cloud and precipitation characteristics on these conditions and stages (Weisman and Klemp, 1982; Houze, 1993).

\subsection{RCE}

Tropical convective systems take about 20 days to reach RCE (Tompkins and Craig, 1998), whereas this study considers a 2-day simulation period. Hence, we do not address aerosol-cloud interactions in RCE where the implications of aerosol-cloud interactions for climate might emerge. However, interestingly, there are similarities between this study and previous studies in RCE (e.g., van den Heever et al., 2011; Grabowski, 2006): (i) van den Heever et al. (2011), Grabowski (2006), and this study, not surprisingly, show very weak changes to domain-averaged cumulative precipitation; (ii) these studies all show significant changes in updraft mass fluxes and the $P$ frequency distribution due to aerosol perturbation, although there are quantitative differences in changes in $P$ frequency distribution. A likely cause of these quantitative differences is the disparity in time available for radiation-cloud interactions to manifest (Zeng et al., 2007; Lee et al., 2012)

\subsection{Raindrop terminal velocity}

Recent studies have linked the characteristics of a convective system to the raindrop terminal velocity (Parodi et al., 2011; Parodi and Emanuel, 2009). Their simulations that differ only in the specification of the raindrop terminal veloc- ity show that cloud size decreases, while updraft strength increases with increasing raindrop terminal velocity. The current model simulations apply the appropriate fall velocities to all precipitating particles based on their temporally and spatially varying mean size. However, to compare our results to these earlier studies, we have calculated the average raindrop terminal velocity for control and perturbed simulations: these are respectively $6.5 \mathrm{~m} \mathrm{~s}^{-1}$ and $7.8 \mathrm{~m} \mathrm{~s}^{-1}$ (temporally and domain-averaged over all regions with mass mixing ratio $\left.>0.05 \mathrm{~g} \mathrm{~kg}^{-1}\right)$. Since raindrop terminal velocity is smaller in the control run than in the high-aerosol run, our results are qualitatively consistent with Parodi et al. (2011) and Parodi and Emanuel (2009): as a result of the aerosol perturbation, the average cloud radius (based on liquid-phase cloud entities) decreases from $7.1 \mathrm{~km}$ to $5.6 \mathrm{~km}$. This broad consistency reinforces the conclusion by Parodi et al. (2011) and Parodi and Emanuel (2009) that raindrop terminal velocity is a fundamental physical parameter that is able to explain variability in the properties of a convective system.

\subsection{Sensitivity to resolution and dimensionality}

The features of simulated MCEs can vary with varying resolutions (e.g., Sato et al., 2008; Donner et al., 1999). To examine the sensitivity of results here to resolution, the highaerosol run and the control run are repeated with a horizontal grid length of $300 \mathrm{~m}$ (reduced from $500 \mathrm{~m}$ ) and a vertical grid length of $120 \mathrm{~m}$ (reduced from $200 \mathrm{~m}$ ); the aspect ratio is maintained. These repeated runs are referred to as the high-aerosol-high-res run and the control-high-res run. Figures $2 c, 3 e$, and $6 b$ for updraft mass flux, WP frequency and homogeneity from these repeated runs, and comparisons between these figures and Figs. 2a, 3c, and 6a from the highaerosol and control runs demonstrate that the qualitative nature of results is relatively insensitive to resolution.

For simulations of observed MCEs over the southern Great Plains, Lee et al. (2008a, b) have shown that aerosolinduced intensification of updrafts and associated microphysical compensation processes are robust to the choice of two vs. three dimensions. Although those simulations were for a different case, the suggestion is that the qualitative character of results presented here is not caused by the twodimensional domain.

\section{Summary and conclusions}

The effects of aerosol on a tropical cloud system driven by deep convection have been investigated. The difference in total precipitation resulting from a 10 -fold increase in aerosol concentration is only $9 \%$ due to compensation among microphysical pathways. While the aerosol perturbation suppresses autoconversion, there is a substantial increase in accretion of cloud liquid by precipitation, which results in the small variation of total surface precipitation. This increase in 
accretion is associated with a significant increase in updraft mass fluxes and condensation.

Although total precipitation amounts are similar, there is a significant difference in the frequency distribution of $P$; with increasing aerosol, there is a marked increase in the occurrence of light and heavy rain, while there is a notable decrease in moderate rain. Changes in the frequency distribution of WP and cloud-top height are qualitatively similar. A strong similarity in the response of the spectral power of the time series of WP and that of updrafts to aerosol perturbation is noted. This similarity indicates that a change in the power of the temporal scale of cloud mass due to an aerosol perturbation tends to be associated with the temporal scale of updrafts.

Most of the differences in the WP frequency at the lower bound of the WP range are noticeable during the early stage of convective activity, while the differences in the WP frequency in the middle WP range emerge during the mature stage of convective activity. The differences in the WP frequency at the upper WP range are manifested during the middle and decaying stages of convective activity.

Increases in the aerosol also result in a significant increase in the spatial homogeneity of the water condensate for most of the simulation period. The differences in the spatial variation, frequency, and power of the WP are substantial at the time of the maximum difference in homogeneity, but significantly less so at the time of the minimum difference.

The difference between the temporal evolution of the WP in high-aerosol and control runs is strongly correlated with that of the precipitation difference, albeit with a lag of $\sim 40$ min.

With increasing aerosol, less radiation enters the domain due to more reflection of incident solar radiation. However, a significant portion of the increase in the reflected radiation is offset by more longwave radiation trapped by the increased ice mass in the upper troposphere. It is notable that with increasing aerosol, longwave radiative heating becomes higher, which in turn causes net radiative heating to be higher. Hence, aerosol-induced changes in longwave radiation tend to compensate for aerosol-induced decreases in solar radiation and associated cooling. However, these changes in radiative heating do not have significant impacts on the qualitative nature of aerosol-related changes in precipitation and WP. Since radiative processes have a much longer timescale than the convective time scale, the 2-day period is likely not long enough to discern radiative impacts on precipitation and WP. A better understanding of the effect of radiative processes merits further studies with longer-period simulations that are matched to the typical durations of aerosol perturbations.

This study shows that average raindrop terminal velocity increases with increasing aerosol, and is accompanied by decreasing cloud size, increasing updraft strength, and the occurrence of heavier precipitation. These changes are consistent with Parodi et al. (2011) and Parodi and Emanuel (2009), who concluded that the raindrop terminal velocity is a physical parameter that, to a large degree, accounts for the cloud system characteristics.

In conclusion, the response of a meteorologically constrained cloud system to an aerosol perturbation is an internal readjustment of precipitation pathways to achieve approximately the same amount of integrated precipitation. A by-product of this readjustment is a significant change in updrafts, condensation, and the spatiotemporal evolution of WP and precipitation frequency.

Acknowledgements. The authors thank NOAA's Climate Goal Program for supporting this work and the HPCC for computing support.

Edited by: H. Su

\section{References}

Abdul-Razzak, H. and Ghan, S. J.: A parameterization of aerosol activation 2. Multiple aerosol types, J. Geophys. Res., 105, 68376844, 2000.

Abdul-Razzak, H. and Ghan, S. J.: A parameterization of aerosol activation - 3. Sectional representation, J. Geophys. Res., 107, D3, doi:10.1029/2001JD000483, 2002.

Barker, H. W.: A parameterization for computing grid averaged solar fluxes for inhomogeneous marine boundary layer clouds. Part I: Methodology and homogeneous biases, J. Atmos. Sci., 53, 2289-2303, 1996.

Batterbury, S. and Warren, A.: The African Sahel 25 years after the great drought: assessing progress and moving towards new agendas and approaches, Global Environ. Change, 11, 1-8, 2001.

Bluestein, H. B.: Synoptic-Dynamic Meteorology in Midlatitudes: Volume II: Observations and Theory of Weather Systems (Synoptic-Dynamic Meteorology in Midlatitudes), Oxford University Press, 594 pp., 1993.

Donner, L. J., Seman, C. J., and Hemler, R. S.: Three-dimensional cloud-system modeling of GATE convection, J. Atmos. Sci., 56, 1885-1912, 1999.

Fan, J., Leung, L. R., Li, Z., Morrison, H., Chen, H., Zhou, Y., Qian, Y., and Wang, Y.: Aerosol impacts on clouds and precipitation in eastern China: Results from bin and bulk microphysics, J. Geophys. Res., 117, D00K36, doi:10.1029/2011JD016537, 2012.

Feingold, G. and Kreidenweis, S. M.: Cloud processing of aerosol as modeled by a large eddy simulation with coupled microphysics and aqueous chemistry, J. Geophys. Res., 107, 4687, doi:10.1029/2002JD002054, 2002.

Flossmann, A. I.: The scavenging of two different types of marine aerosol particles using a two-dimensional detailed cloud model, Tellus B, 43, 301-321, doi:10.1034/j.1600-0889.1991.t01-200004.x, 1991.

Fridlind, A., Ackerman, A., Petch, J., Field, P., Hill, A., McFarquhar, G., Xie, S., and Zhang, M.: ARM/GCSS/SPARC TWPICE intercomparison study, available at: http://science.arm.gov/ wg/cpm/scm/scmic6/index.html, 2009.

Fridlind, A., Ackerman, A., Chaboureau, J.-P., Fan, J., Grabowski, W. W., Hill, A., Jones, T. R., Khaiyer, M. M., Liu, G., Minnis, 
P., Morrison, H., Nguyen, L., Park, S., Petch, J. C., Pinty, J.-P., Schumacher, C., Shipway, B., Varble, A. C., Wu, X., Xie, S., and Zhang, M.: A comparison of TWP-ICE observational data with cloud-resolving model results, J. Geophys. Res., 117, D05204, doi:10.1029/2011JD016595, 2012.

Grabowski, W. W.: Indirect Impact of Atmospheric Aerosols in Idealized Simulations of Convective-Radiative Quasi Equilibrium, J. Climate, 19, 4664-4682, doi:10.1175/JCLI3857.1, 2006.

Houze, R. A.: Cloud dynamics, Academic Press, 573 pp., 1993.

Khain, A., Rosenfeld, D., and Pokrovsky, A.: Aerosol impact on the dynamics and microphysics of deep convective clouds, Q. J. Roy. Meteorol. Soc., 131, 2639-2663, 2005.

Khain, A., BenMoshe, N., and Pokrovsky, A.: Factors determining the impact of aerosols on surface precipitation from clouds: Attempt of classification, J. Atmos. Sci., 65, 1721-1748, 2008a.

Khairoutdinov, M. F. and Yang, C.-E.: Cloud-resolving modelling of aerosol indirect effects in idealised radiative-convective equilibrium with interactive and fixed sea surface temperature, Atmos. Chem. Phys., 13, 4133-4144, doi:10.5194/acp-13-41332013, 2013.

Koren, I., Altaratz, O., Remer, L. A., Feingold, G., Martins, J. V., and Heiblum, R. H.: Aerosol-induced intensification of rain from the tropics to the mid-latitude, Nat. Geosci., 5, 118-122, 2012.

Lee, S. S.: Aerosols, clouds and climate, Nat. Geosci., 4, 826-827, 2011.

Lee, S. S. and Feingold, G.: Precipitating cloud-system response to aerosol perturbations, Geophys. Res. Lett., 37, L23806, doi:10.1029/2010GL045596, 2010.

Lee, S. S., Donner, L. J., Phillips, V. T. J., and Ming, Y.: Examination of aerosol effects on precipitation in deep convective clouds during the 1997 ARM summer experiment, Q. J. Roy. Meteorol. Soc., 134, 1201-1220, doi:10.1002/qj.287, 2008a.

Lee, S. S., Donner, L. J., Phillips, V. T. J., and Ming, Y.: The dependence of aerosol effects on clouds and precipitation on cloudsystem organization, shear and stability, J. Geophys. Res., 113, D16202, doi:10.1029/2007JD009224, 2008b.

Lee, S. S., Donner, L. J., and Phillips, V. T. J.: Sensitivity of aerosol and cloud effects on radiation to cloud types: comparison between deep convective clouds and warm stratiform clouds over one-day period, Atmos. Chem. Phys., 9, 2555-2575, doi:10.5194/acp-9-2555-2009, 2009.

Lee, S. S., Feingold, G., and Chuang, P. Y.: Effect of aerosol on cloud-environment interactions in trade cumulus, J. Atmos. Sci., 69, 3607-3632, 2012.

Li, Z., Niu, F., Fan, J., Liu, Y., Rosenfeld, D., and Ding, Y.: Longterm impacts of aerosols on the vertical development of clouds and precipitation, Nat. Geosci., 4, 888-894, 2011.

May, P. T., Mather, J. H., Vaughan, G., and Jakob, C.: Characterizing oceanic convective cloud systems - The Tropical Warm Pool International Cloud Experiment, B. Am. Meteorol. Soc., 154, 153155, doi:10.1175/BAMS-89-2-153, 2008.

Morrison, H. and Grabowski, W. W.: Cloud-system resolving model simulations of aerosol indirect effects on tropical deep convection and its thermodynamic environment, Atmos. Chem. Phys., 11, 10503-10523, doi:10.5194/acp-11-10503-2011, 2011.

Parodi, A. and Emanuel, K.: A theory for buoyancy and velocity scales in deep moist convection, J. Atmos. Sci., 66, 3449-3463, 2009.
Parodi, A., Foufoula-Georgiou, E., and Emanuel, K.: Signature of microphysics on spatial rainfall statistics, J. Geophys. Res., 116, D14119, doi:10.1029/2010JD015124, 2011.

Respondek, P. S., Flossmann, A. I., Alheit, R. R., and Pruppacher, H. R.: A theoretical study of the wet removal of atmospheric pollutants. Part V: The uptake, redistribution and deposition of $\left(\mathrm{NH}_{4}\right)_{2} \mathrm{SO}_{4}$ by a convective cloud containing ice using a two-dimensional cloud dynamics model with detailed microphysics, J. Atmos. Sci., 52, 2121-2132, doi:10.1175/15200469(1995)052<2121:ATSOTW>2.0.CO;2, 1995.

Saleeby, S. M. and Cotton, W. R.: A large-droplet mode and prognostic number concentration of cloud droplets in the Colorado state university regional atmospheric modeling system (RAMS). Part I: Module description and supercell test simulations, J. Appl. Meteorol., 43, 182-195, 2004.

Sato, T., Yoshikane, T., Satoh, M., Miura, H., and Fujinami, H.: Resolution dependency of the diurnal cycle of convective clouds over the Tibetan plateau in a mesoscale model, J. Meteorol. Soc. Jpn., 86A, 17-31, 2008.

Seifert, A., Köhler, C., and Beheng, K. D.: Aerosol-cloudprecipitation effects over Germany as simulated by a convectivescale numerical weather prediction model, Atmos. Chem. Phys., 12, 709-725, doi:10.5194/acp-12-709-2012, 2012.

Seo, E. K. and Liu, G.: Determination of 3D cloud ice water contents by combining multiple data sources from satellite, ground radar, and a numerical model, J. Appl. Meteorol. Clim., 45, 1494-1504, 2006.

Solomon, S., Qin, D., Manning, M., Alley, R. B., Berntsen, T., Bindoff, N. L., Chen, Z., Chidthaisong, A., Gregory, J. M., Hegerl, G. C., Heimann, M., Hewitson, B., Hoskins, B. J., Joos, F., Jouzel, J., Kattsov, V., Lohmann, U., Matsuno, T., Molina, M., Nicholls, N., Overpeck, J., Raga, G., Ramaswamy, V., Ren, J., Rusticucci, M., Somerville, R., Stocker, T. F., Whetton, P., Wood, R. A., and Wratt, D.: Technical Summary, in: Climate Change 2007: The Physical science basis. Contribution of working group I to the fourth assessment report of the intergovernmental panel on climate change, edited by: Solomon, S., Qin, D., Manning, M., Chen, Z., Marquis, M., Averyt, K. B., Tignor, M., and Miller, H. L., Cambridge University Press, Cambridge, United Kingdom and New York, NY, USA, 2007.

Tao, W.-K., Simpson, J., Baker, D., Braun, S., Chou, M.-D., Ferrier, B., Johnson, D., Khain, A., Lang, S., Lynn, B., Shie, C.-L., Starr, D., Sui, C.-H., Wang, Y., and Wetzel, P.: Microphysics, radiation and surface processes in the Goddard Cumulus Ensemble (GCE) model, Meteorol. Atmos. Phys., 82, 97-137, 2003.

Tao, W.-K., Chen, J.-P., Li, Z., Wang, C., and Zhang, C.: Impact of aerosols on convective clouds and precipitation, Rev. Geophys., 50, RG2001, doi:10.1029/2011RG000369, 2012.

Tompkins, A. M. and Craig, G. C.: Radiative-convective equilibrium in a three-dimensional cloud ensemble model, Q. J. Roy. Meteor. Soc., 124, 2073-2098, 1998.

van den Heever, S. C. and Cotton, W. R.: Urban aerosol impacts on downwind convective storms, J. Appl. Meteorol. Clim., 46, 828-850, 2007.

van den Heever, S. C., Stephens, G. L., and Wood, N. B.: Aerosol indirect effects on tropical convection characteristics under conditions of radiative-convective equilibrium, J. Atmos. Sci., 68, 699-718, 2011. 
Vaughan, G., Schiller, C., MacKenzie, A. R., Bower, K., Peter, T., Schlager, H., Harris, N. R. P, and May, P. T.: Studies in a natural laboratory: High-altitude aircraft measurements around deep tropical convection, B. Am. Meteorol. Soc., 88, 647-662, 2008.

Wang, Y., Wan, Q., Meng, W., Liao, F., Tan, H., and Zhang, R.: Long-term impacts of aerosols on precipitation and lightning over the Pearl River Delta megacity area in China, Atmos. Chem. Phys., 11, 12421-12436, doi:10.5194/acp-11-12421-2011, 2011.

Weisman, M. L. and Klemp, J. B.: The dependence of numerically simulated convective storms on vertical wind shear and buoyancy, Mon. Weather Rev., 110, 504-520, 1982.

Xu, K.-M., Cederwall, R. T., Donner, L. J., Grabowski, W. W., Guichard, F., Johnson, D. E., Khairoutdinov, M., Krueger, S. K., Petch, J. C., Randall, D. A., Seman, C. J., Tao, W.-K, Wang, D., Xie, S. C., Yio, J. J., and Zhang, M.-H.: An intercomparison of cloud-resolving models with the Atmospheric Radiation Measurement summer 1997 Intensive Observation Period data, Q. J. Roy. Meteor. Soc., 128, 593-624, 2002.
Yin, Y., Wurzler, S., Levin, Z., and Reisin, T. G.: Interactions of mineral dust particles and clouds: Effects on precipitation and cloud optical properties, J. Geophys. Res., 107, 4724, doi:10.1029/2001JD001522, 2002.

Zeng, X., Tao, W.-K., Zhang, M., Peters-Lidard, C., Lang, S., Simpson, J., Kumar, S., Xie, S., Eastman, J., and Shie, C.-L.: Evaluating clouds in long-term cloud-resolving model simulations with observational data, J. Atmos. Sci., 64, 4153-4177, 2007. 